\title{
Long-term monitoring of a winter bat assemblage revealed large fluctuations and trends in species abundance
}

${ }^{1}$ Department of Nature

Education and Conservation, Adam Mickiewicz University in Poznań Corresponding author, E-mail: rbernard@amu. edu.pl

${ }^{2}$ Polish Society for Nature Conservation "Salamandra"

${ }^{3}$ Poznańska 72, PL-62080 Tarnowo Podgórne. Poland

${ }^{4}$ Department of Avian Biology and Ecology, Adam Mickiewicz University in Poznań

\author{
Rafał Bernard ${ }^{1 *}$, Radosław Jaros ${ }^{2}$, Juliusz Samoląg ${ }^{3}$ and Jakub Z. Kosicki ${ }^{4}$
}

\section{ABSTRACT}

Monitoring studies in Strzaliny, one of the greatest hibernacula in Poland, comprised 31 annual bat censuses (1989-2019). The abundance peaked in 2002 for Myotis myotis, 2009 for Myotis nattereri and 2008 for the whole assemblage. Comparison of the maximum abundance in the monitoring period with that from 1980 to 1982 showed an almost fourfold increase for the whole assemblage, tenfold increase for $M$. nattereri and fourfold increase for M. myotis.

In 1989-2019, the numbers of M. myotis, M. nattereri, Myotis daubentonii and Plecotus auritus were fluctuating, but most of the recorded changes could not be explained by methodological problems or a direct human impact. Therefore, the cumulative results largely reflected the real trends in the species abundance. A long-term upward trend in the whole bat assemblage was recognisable, but with a stable or slightly decreasing phase in the last decade. An upward trend in M. nattereri was even stronger and has only slightly flattened recently. In M. myotis, the trend was clearly upwards up to the early 2000s, but weakly downwards in the following years. In $M$. daubentonii and $P$. auritus, no significant trend was determined. In strongly fluctuating $M$. daubentonii, the numbers were mostly moderate or high, and even increasing, up to 2008 and only moderate or low in the following years. In P. auritus, an increase occurred in the 1980 s and early 1990 s, and then, after the stochastic human-induced drop in 1994, its abundance remained relatively stable.

The population trends in Strzaliny largely reflected the general trends assessed for a large part of Europe. This suggests that the general population trends may be recognisable even in one large winter assemblage if it is reliably and consistently monitored through a long period. In this context, the hibernaculum in Strzaliny appeared to be a model object for such studies.

KEYWORDS

Chiroptera, Myotis myotis, Myotis nattereri, Myotis daubentonii, Plecotus auritus, population dynamics, population trend, Poland (c) BY-NC-ND

019 Rafał Bernard et al.

This is an open access article distributed under the Creative Commons Attribution-NonCommercial-NoDerivs license

\section{INTRODUCTION}

Abundance of many species significantly changes in time as a result of, for example, habitat and climate changes, human impact or stochastic events. Numbers of bats observed in hibernacula frequently differ between periods and even subsequent years. These differences are often hard to explain due to many potential causes, frequently unrecognisable in a particular case. Irrespective of these difficulties, local and large-scale monitoring of bat abundance is important for the conservation policy and management of both bats and their habitats.

Preliminary research in Strzaliny was carried out in 1980-1982. Main monitoring studies started there after a break, from the end of the 1980s. They included both studies of the seasonal population dynamics in a winter bat assemblage (1989-1990) and the 31-year-long monitoring of species numbers between 1989 and 2019. Data from the 1980s and 1990s were mostly published (Bernard et al., 1991; Bernard \& Samoląg, 1991, 2002a,b; Bernard, 1994), while those collected in the last 20 years have practically remained unpublished apart from a record of Myotis bechsteinii (Wojtaszyn et al., 2008).

Bat research in Strzaliny was conducted during a period combining climate change and increasing human care about the environment in Europe. Therefore, the recorded bat abundance was highly valuable not only in the assessment of the local conservation status of a particular species, but also for recognition of changes in population numbers and their interpretation.

The main aim of this paper is to a) recognise dynamics and trends in bat abundance on the basis of long-term mon- 
itoring in Strzaliny and b) find answer for the question to what extent data from one large winter bat assemblage may reflect species dynamics and trends in a larger territorial scale.

\section{MATERIALS AND METHODS}

The studied object, being part of "Die Pommernstellung", a fortified defensive line built by the Germans in the 1930s, is situated southeast of the Strzaliny village, with the entrance at $53^{\circ} 11^{\prime} 09^{\prime \prime} \mathrm{N}$ and $16^{\circ} 13^{\prime} 11^{\prime \prime} \mathrm{E}$, UTM $33 \mathrm{U}$ WU89. Surface fortifications are largely destroyed, while their underground part is fairly well preserved. It is located 11-12 m below the surface of the earth and includes ca. $540 \mathrm{~m}$ of still available corridors and chambers. They consist of a) $225 \mathrm{~m}$ of the main corridor, $3 \mathrm{~m}$ wide and $2.8 \mathrm{~m}$ high, with five side chambers and b) ca. $315 \mathrm{~m}$ of narrow corridors, $1.4 \mathrm{~m}$ wide and $2.3 \mathrm{~m}$ high (Bernard et al., 1991; Bernard \& Samoląg, 2002a). The main corridor is characterised by slightly lower winter temperatures, between $3.0^{\circ} \mathrm{C}$ and $7.8^{\circ} \mathrm{C}$ in various sections, and higher humidity $(80 \%-96 \%)$, while the narrow corridors are warmer $\left(7.8^{\circ} \mathrm{C}-9.6^{\circ} \mathrm{C}\right)$ and less humid (69\%-80\%). Crevices of various depths in thick concrete walls and ceilings are abundant in the main corridor and chambers, but are uncommon and local in the narrow corridors. Bats enter the underground hibernaculum both through the staircase at one end of the main corridor and a deep shaft at the other end of it. Through the latter, cold air penetrates the adjacent underground section. However, the underground complex is generally quite well isolated from the surface conditions, and temperatures are relatively stable in most of it.

The object has been protected as a nature reserve "Strzaliny koło Tuczna" since 2008 and as a Natura 2000 Site of Community Importance PLH320021 since 2009. In the past, it was unrestrictedly touristically used for a long time. Since 2011, the human impact has been limited to controlled tourism in the period between mid-April and mid-September.

Monitoring censuses in 1989-2019 were always conducted a) once a year, during 1 day in an advanced hibernation period between February 2 and 16 ; b) by a team of two to four people, with R. Bernard and J. Samoląg since 1989 and additionally R. Jaros since 2004 and c) according to a highly unified set of methods providing the best possible results in specific and difficult conditions of the Strzaliny underground complex. Observers moved on the same route each year. All openings, cracks and crevices in the walls and ceilings were controlled. In 2013, an endoscope with a camera and screen for image capture was additionally used to check the invisible space in deep crevices or behind the first line of bats 'clogging up' crevices. However, the individuals found using this deep penetration method were not included in the census results. Rings were read only in easily accessible individuals hibernating outside the crevices. Microclimatic conditions in the underground corridors, such as air temperature and relative humidity, were measured using Assmann psychrometer and data loggers.

Dataset is a time series, and therefore, it suffers from serial auto-correlation (i.e. bat abundance in any particular year depends on the values of bat abundance in previous years); so, we used non-parametric Mann-Kendall test for trend analysis. According to this procedure, we assessed if there was a monotonic (positive or negative) trend of population size over time. Data from preliminary research in comparable winter dates in 1980-1982 (Bernard et al., 1991) were used as a comparative background for the results from 1989 to 2019 to complete a picture of long-term changes. Due to the 6-year gap separating them from the main monitoring studies, they were not used in trend calculation.

\section{RESULTS}

Eight bat species were recorded: Myotis daubentonii (Kuhl, 1817), Myotis dasycneme (Boie, 1825), Myotis brandtii (Eversmann, 1845)/Myotis mystacinus (Kuhl, 1817), Myotis nattereri (Kuhl, 1817), Myotis bechsteinii (Kuhl, 1817), Myotis myotis (Borkhausen, 1797), Plecotus auritus (Linnaeus, 1758) and Barbastella barbastellus (Schreber, 1774) (Table 1). Two individuals were undoubtedly identified as $M$. brandtii, but 19 other remained indeterminate between $M$. brandtii and $M$. mystacinus, hence we treated all the 21 individuals as $M$. brandtii/ mystacinus.

The assemblage core comprised the same four species, that is, M. nattereri, M. myotis, $M$. daubentonii and $P$. auritus, during all censuses (Table 1). However, the percentages of particular species varied between years: $P$. auritus was the most numerous species in the assemblage in 1980-1982 (3 censuses), M. myotis in 1989-1990 and 1996-2002 (9 censuses) and M. nattereri in 1991-1995 and 2003-2019 (22 censuses).

The total number of hibernating bats almost doubled between the end of the preliminary research (1982) and the beginning of the monitoring study (1989) (Table 1). During the first 20 years of the monitoring study, it was strongly fluctuating, but generally increasing, with a peak in 2007-2009. The

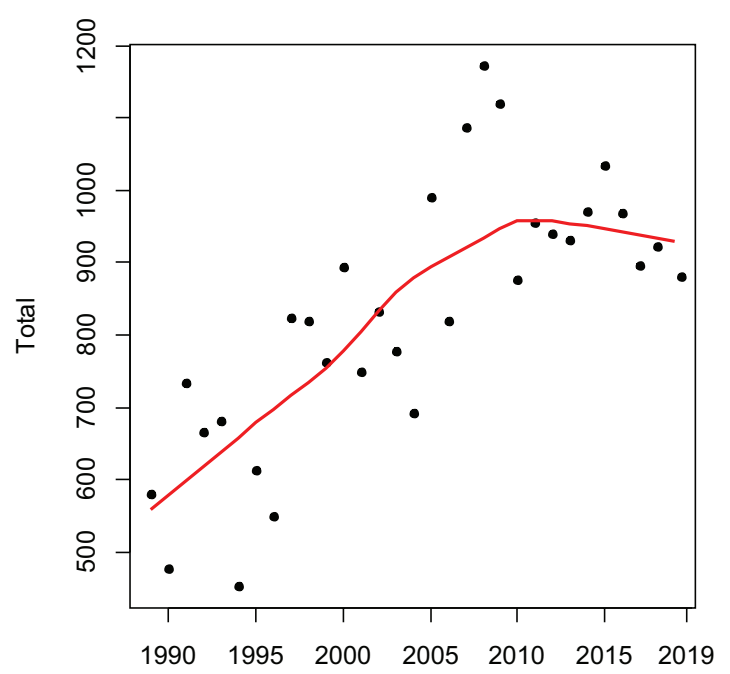

Figure 1. Changes and a long-term trend in the total abundance of the bat assemblage in Strzaliny in 1989-2019 
Table 1. Number of bats recorded in Strzaliny during particular winter censuses in 1980-1982 and 1989-2019

\begin{tabular}{|c|c|c|c|c|c|c|c|c|c|c|}
\hline Year & MNA & MMY & MDA & PAU & МMB & BAR & MDS & MBE & Indet. & Total \\
\hline 1980 & 5 & 65 & 43 & 66 & & & & & & 179 \\
\hline 1981 & 34 & 49 & 67 & 87 & & & & & & 237 \\
\hline 1982 & 58 & 79 & 81 & 82 & & & & & & 300 \\
\hline 1989 & 132 & 158 & 125 & 151 & & & & & 16 & 582 \\
\hline 1990 & 106 & 162 & 115 & 78 & & & & & 18 & 479 \\
\hline 1991 & 256 & 148 & 185 & 124 & & & & & 22 & 735 \\
\hline 1992 & 212 & 164 & 142 & 131 & & & & & 18 & 667 \\
\hline 1993 & 258 & 156 & 143 & 120 & & & & & 5 & 682 \\
\hline 1994 & 151 & 143 & 84 & 65 & & & & & 10 & 453 \\
\hline 1995 & 208 & 177 & 148 & 64 & & & & & 18 & 615 \\
\hline 1996 & 169 & 207 & 93 & 61 & & & & & 21 & 551 \\
\hline 1997 & 244 & 301 & 199 & 66 & & & & & 15 & 825 \\
\hline 1998 & 261 & 274 & 206 & 66 & & & & & 14 & 821 \\
\hline 1999 & 218 & 278 & 197 & 57 & & & & & 12 & 762 \\
\hline 2000 & 272 & 295 & 246 & 65 & & & & & 17 & 895 \\
\hline 2001 & 270 & 282 & 129 & 45 & & & & & 24 & 750 \\
\hline 2002 & 276 & 316 & 166 & 61 & & & & & 15 & 834 \\
\hline 2003 & 309 & 237 & 143 & 62 & & & & & 28 & 779 \\
\hline 2004 & 236 & 224 & 159 & 54 & & & & & 19 & 692 \\
\hline 2005 & 414 & 237 & 255 & 62 & & & & & 23 & 991 \\
\hline 2006 & 370 & 206 & 159 & 61 & & & & & 24 & 820 \\
\hline 2007 & 488 & 231 & 294 & 58 & & & & 1 & 15 & 1,087 \\
\hline 2008 & 495 & 275 & 301 & 73 & & & 1 & 1 & 26 & 1,172 \\
\hline 2009 & 583 & 267 & 156 & 77 & 1 & & 1 & & 36 & 1,121 \\
\hline 2010 & 487 & 206 & 95 & 64 & 1 & & & & 24 & 877 \\
\hline 2011 & 452 & 264 & 142 & 76 & & & 1 & & 21 & 956 \\
\hline 2012 & 498 & 255 & 97 & 68 & 1 & & 1 & & 21 & 941 \\
\hline 2013 & 523 & 245 & 101 & 53 & & & & & 9 & 931 \\
\hline 2014 & 516 & 275 & 112 & 55 & 2 & & 1 & & 11 & 972 \\
\hline 2015 & 499 & 289 & 160 & 67 & 4 & & 1 & & 15 & 1,035 \\
\hline 2016 & 489 & 251 & 148 & 62 & 2 & 3 & 1 & & 12 & 968 \\
\hline 2017 & 417 & 231 & 140 & 84 & 7 & 6 & 1 & & 11 & 897 \\
\hline 2018 & 483 & 190 & 164 & 68 & & 3 & 1 & & 15 & 924 \\
\hline 2019 & 502 & 152 & 147 & 63 & 3 & 4 & & & 13 & 884 \\
\hline
\end{tabular}

The bat species are arranged according to lowering abundance.

Key: BAR, Barbastella barbastellus; Indet., indeterminate; MBE, Myotis bechsteinii; MDA, Myotis daubentonii; MDS, Myotis dasycneme; MMB, Myotis mystacinus/ brandtii; MMY, Myotis myotis; MNA, Myotis nattereri; PAU, Plecotus auritus.

maximum population number of the whole bat assemblage was two times as large as the number in the beginning of the monitoring study and almost four times as large as the highest number during the preliminary research. In the next years, the total number remained at a lower, but still fairly high level (Table 1 and Figure 1). A clear upward population trend of the whole bat assemblage was recognisable for the large part of the 31-year-long monitoring study, with a stable or slightly decreasing phase in the last decade $(\tau=0.58, p<0.0001$; Figure 1$)$.

M. nattereri was quite rare in the early 1980 s, but already more than twice such numerous in the end of the de- cade, in the beginning of the monitoring study (Table 1). Irrespective of some fluctuations during the monitoring study, the abundance was significantly increasing during a long period up to 2009 , when it reached its maximum, being 4.4 times as large as the number in 1989 and even 10 times as large as the highest number during the preliminary research in the beginning of the 1980s (Table 1 and Figure 2A). Then it remained at its high level up to the recent census. For the entire 31-year-long monitoring study, a clear upward trend was noticed, with a slightly flattened phase in the last decade $(\tau=0.71, p<0.0001$; Figure $2 \mathrm{~A})$. 

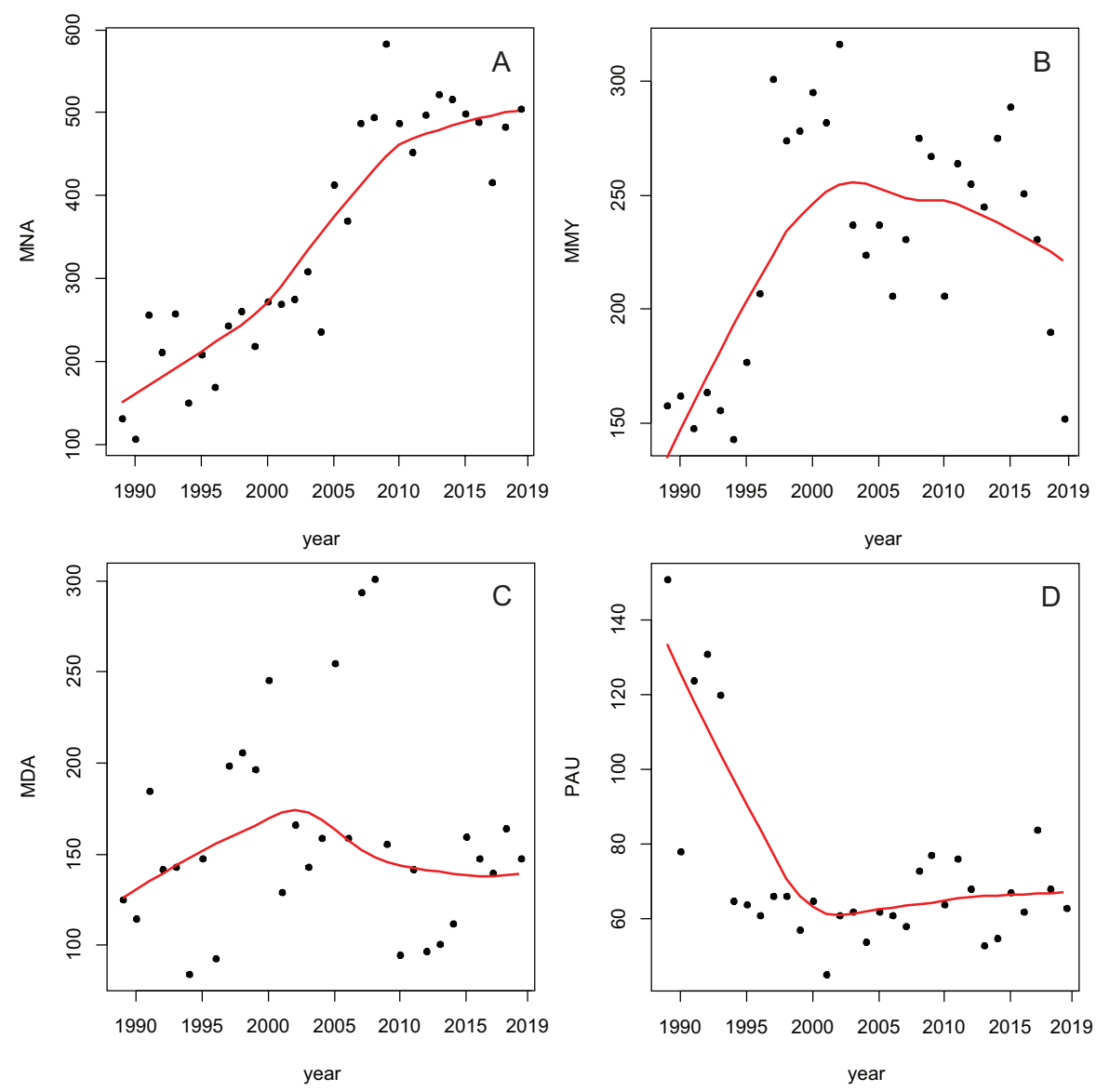

Figure 2. Changes and long-term trends in the abundance of four major bat species in Strzaliny in 1989-2019 Key: MDA, Myotis daubentonii; MMY, Myotis myotis; MNA, Myotis nattereri; PAU, Plecotus auritus.

The number of wintering M. myotis doubled between the preliminary research period (1982) and the beginning of the monitoring study (1989) (Table 1). It remained relatively stable at a moderate level (ca. 150 individuals) from 1989 to 1994 , and then increased continuously and fast up to 1997 . The high level continued during the six subsequent censuses, with the maximum recorded in 2002, wherein it was two times as large as in 1989 and four times as large as the highest number in the beginning of the 1980 s (Table 1 and Figure 2B). In the following years, the number fluctuated with a recognisable lower level between 2003 and 2007 and a higher level between 2008 and 2015. In the recent 4 years, the number has gradually decreased to the level recorded at the beginning of the monitoring study. The trend was clearly upwards up to the early 2000s, but weakly downwards in the following years $(\tau=0.30, p=$ 0.023; Figure 2B).

The difference in the abundance of $M$. daubentonii between the beginning and the end of the 1980s was not as great as in the previous two species (Table 1). Then, during the long monitoring study, it was strongly fluctuating with subsequent years or longer phases of low and high numbers. For example, the abundance reached the highest level in 2007-2008 and then rapidly decreased by ca. $50 \%$ from year to year. The maximum population number was 2.4 times as large as the number in 1989 and 3.7 times as large as the highest number during the preliminary research in the beginning of the 1980s (Table 1 and Figure 2C). For the entire 31-year-long monitoring study, no significant trend was determined $(\tau=0.02, p=$ 0.86 ; Figure $2 \mathrm{C}$ ). However, the numbers were mostly moderate or high, and even increasing, up to 2008 and only moderate or low in the following years.

The abundance of $P$. auritus was the highest at the beginning of the monitoring study, in 1989 (151 individuals), being almost two times as large as that recorded during the preliminary research in 1982 (Table 1 and Figure 2D). It remained high up to 1993 , but rapidly and significantly decreased in 1994 . From that census, the abundance stayed relatively low and stable, with fluctuations between 45 and 84 individuals. No significant long-term trend was observed for the entire monitoring study ( $\tau=-0.22, p=0.09$; Figure 2D).

Other bat species appeared during February censuses very late, beginning from 2007. Four species, M. bechsteinii, $M$. dasycneme, M. brandtii/mystacinus and B. barbastellus, occurred in very low numbers (only one to seven individuals per census; Table 1). The last three species constituted, however, quite a stable accessory component of the assemblage in recent years. 
Endoscope checking of the space invisible to the naked eye showed that the seemingly deep crevices were mostly shallower than previously assumed and their invisible sections were mostly unfavourable for bats and unoccupied by them. Only 10 individuals were locally found there, that is, $1.06 \%$ of the total assemblage number. They were not included in the results to save comparativeness of the data with those collected in other years.

\section{DISCUSSION}

During the entire study period, the underground in Strzaliny did not change significantly and all its sections were fully searchable. The full accessibility excluded an influence of uncounted bats from inaccessible sections on the recorded numbers. What is more, the recorded differences in the numbers of particular species did not result either from variable methods or from diverse numbers of uncounted bats hidden deeply in the crevices. The problem of uncounted bats in inaccessible shelters might have influenced the numbers recorded in many other hibernacula in Poland as the authors' own experience showed and as, for example, Fuszara and Fuszara (2002) suggested for the Modlin fortress. In Strzaliny, the consistent application of methods by the same people minimised potential mistakes and differences that are an effect of personal approach and skills, and thus assured high reliability and comparativeness of data. The testing endoscope study convincingly showed that only very rare individuals were invisible to the naked eye. Therefore, potential mistake, if occurred, must have been very small (ca. $1 \%)$. The recorded changes in the numbers of wintering bats were, therefore, certainly real.

Both natural and anthropogenic factors might have been causative of these changes. A long-term increase in bat assemblage suggested that balanced touristic penetration did not influence most of the observed changes in numbers. A clear negative human impact was recorded only twice. Very low number of bats in 1994 (Table 1 and Figures 1 and 2) was a consequence of fire made in the underground corridor by thoughtless tourists, especially of an irritating fume that was detectable for a long time (Bernard \& Samoląg, 2002a). It seems that this event might have had long-lasting consequences in $P$. auritus, whose numbers remained relatively low after this decrease. Population numbers of the other three species recovered in the next year (Table 1 and Figure 2). A similar fire and firecracker during New Year's Eve in 2017/2018 was mainly followed by bats' shift to other sections of the underground, and rather not by a significant drop in their abundance. Only the number of freely hanging $M$. myotis might have been decreased by this situation.

As most of the recorded changes and trends could not be explained by methodological problems and a direct human impact, other factors and phenomena could have been crucial for their occurrence. First of all, it should be stressed that the hibernaculum in Strzaliny seems to be optimal for long-term monitoring and tracking trends. It is situated in a large forest complex and not in the proximity of other known large hibernacula. As a consequence, large-scale exchange of individuals between Strzaliny and other hibernacula during an advanced hibernation season seems to be improbable. What is more, such an exchange between subsequent winters might have been relatively low. This supposition was supported by the high rate of recovery data of ringed bats that reflected their high site fidelity. In 1980-1981, 216 individuals were ringed in Strzaliny and $43.1 \%$ of them were recovered from there in the next winter season after ringing: from $27.7 \%$ in $M$. nattereri, through $34.3 \%$ in $M$. daubentonii and $38.6 \%$ in $P$. auritus, up to $64.1 \%$ in $M$. myotis. Ringed individuals numbering $1-12$, mostly of $M$. myotis and $P$. auritus, were still recorded yearly in 1989-1995 and exceptionally in 1999 (Bernard \& Samoląg, 2002b). These conditions led the authors to assume that the trends in Strzaliny were not strongly influenced by wintering of the same individuals in various hibernacula in various years. In the authors' opinion, this aspect might have influenced the observed abundance stronger, when it had been studied in only selected objects in an area with many potential uncontrolled hibernacula, for example, in studies conducted in central and northeastern Poland (see Fuszara et al., 2010).

Elimination or minimising of subsequent reasons led the authors to conclude that the changes in bat numbers in Strzaliny and their trends largely reflected the real changes in population numbers of particular species during these 40 years. In this context, hibernaculum in Strzaliny appears to be a model object for such studies.

An increase in abundance of all the four core species in Strzaliny between the beginning and the end of the 1980s probably coincided with the general trend of recovery of the bat population after a dramatic decline in an earlier period (e.g. Stebbings, 1988; Horáček, 2010). However, the trends were different for a particular species in the next 30 years.

The long-term upward trend of $M$. nattereri was not only local, typical of Strzaliny, but also more general, supranational, recorded in 1993-2011 for several European countries in various biogeographical regions (Haysom et al., 2013; Van der Meij et al., 2015). This upward trend was assessed in total as moderate for countries included in the report on European bat population trends (Haysom et al., 2013) and was less positive for the Continental region (including some Central European countries, but not Poland) than for the Atlantic region (Van der Meij et al., 2015). In Strzaliny, this trend was even strong, corresponding to an increase recorded in some other large hibernacula in Poland (Jurczyszyn et al., 2002; Fuszara et al., 2010; Lesiński et al., 2011). However, the increase recorded in Strzaliny was the largest in the published data known to the authors.

Regarding M. myotis, the clear upward trend observed in Strzaliny up to the early 2000s corresponded to an increase in another large Polish hibernaculum, the Szachownica Cave (central Poland) during 1982-2010 (Lesiński et al., 2011), and to a moderate increase for some European countries during 1993-2011 (Haysom et al., 2013; Van der Meij et al., 2015). However, the study period in Strzaliny was 12 years longer than 
for the European general data and comprised quite large fluctuations of numbers in the 2000s and 2010s and their clear recent decrease. This made the local species trend weakly downwards for the second half of the monitoring period. Due to the lack of comparable European general data, it was unclear whether this decline also occurred on a larger scale.

For $M$. daubentonii, the population trend between 1993 and 2011 was found to be a moderate increase for assessed several European countries (Haysom et al., 2013; Van der Meij et al., 2015), while no significant trend was recognisable in Strzaliny due to strong and continuous fluctuations. A significantly longer period of studies in Strzaliny, with generally lower numbers in the last decade, might have also influenced this difference. However, some similarities in the species dynamics were noticeable. In Strzaliny, higher numbers of $M$. daubentonii were recorded only till 2008. In some other Polish hibernacula, the numbers rose till the early 2000s and then they tended to fall (Fuszara et al., 2010; Lesiński et al., 2011). Also, even in the European general data (Haysom et al., 2013), an increase was recognisable up to the beginning of the 2000s, followed by a more stable phase of slightly lower numbers.

$P$. auritus was the only one species in Strzaliny whose recent numbers have been found to be similar to or even smaller than those recorded in the beginning of the 1980s. However, this picture was artificial as they were significantly higher temporarily (1989-1993) and then significantly dropped in 1994 as an effect of a stochastic event. In this resident species, which rarely migrates further than $10 \mathrm{~km}$ (Dietz et al., 2007; Steffens et al., 2007), wintering individuals must have originated from the nearest surrounding area. Thus, the results from Strzaliny might have reflected the relatively stable population number in the vicinity for many years. These data might have followed a stable trend assessed for several European countries for a shorter period between 1993 and 2011 (Haysom et al., 2013; Van der Meij et al., 2015). However, no clear trend was readable in Strzaliny for 1989-2019, possibly due to the humaninduced strong decline mentioned above. Local situation in large hibernacula could have been different as a clear increase was recorded in Polish Szachownica Cave during 1982-2010 (Lesiński et al., 2011).

It should be stressed that the local population dynamics and trends, recorded in the four major bat species in Strzaliny (Northwest Poland), largely corresponded to those observed in some other Polish hibernacula (Jurczyszyn et al., 2002; Fuszara et al., 2010; Lesiński et al., 2011). What is more, they also largely reflected the general population trends assessed in a large part of Europe (Haysom et al., 2013; Van der Meij et al., 2015). This suggests that large-scale population tendencies and trends may be quite reliably recognisable even in one large winter assemblage if it is reliably and consistently monitored through a long period and if the hibernaculum is a) not situated in the proximity of other large hibernacula, b) largely searchable and c) stable in the aspects of conditions and hiding places.

\section{Acknowledgements}

The authors are very grateful to Radosław Dzięciołowski, Krzysztof Dzięgielewski, Andrzej Gawlak, Grzegorz Gołębniak, Karolina Jamska, Mirosław Jurczyszyn, Tomasz Kalinowski, Magdalena Karbowska-Dzięgielewska, Andrzej Kepel, Rafał Kurczewski, Tomasz Mazur, Marek Niezabitowski, Klaudia Samoląg, Agnieszka Szubert-Kruszyńska, Andrzej Stępka, Andrzej Węgiel, Wiesław Węgiel, Bartosz Zwoliński, Rafał Zwoliński, and the Tuczno Forest District for their help in taking bat censuses.
Bernard, R. (1994) Dekady Spisu Nietoperzy (1989-1992) na Pomorzu Zachodnim [Bat censuses (DSN: 1989-1992) in the Western Pomerania region]. In: B.W. Wołoszyn (ed.), Zimowe spisy nietoperzy w Polsce: 1988-1992. Wyniki i ocena skuteczności [Results of the winter bat census in Poland: 1988-1992] (pp. 29-40). Kraków: Chiropterological Information Center ISEZ PAN.

Bernard, R., Głazaczow, A. \& Samoląg, J. (1991) Overwintering bat colony in Strzaliny (North-Western Poland). Acta Zoologica Cracoviensia 34: 453-461.

Bernard, R. \& Samoląg, J. (1991) Nowe stanowisko nocka Bechsteina, Myotis bechsteini (Kuhl, 1818) w północno-zachodniej Polsce [New locality of the Bechstein's bat Myotis bechsteini (Kuhl, 1818) in north-western Poland]. Lubuski Przegląd Przyrodniczy 2(1): 47-49.

Bernard, R. \& Samoląg, J. (2002a) Dekady Spisu Nietoperzy 1993-1999 w Strzalinach (północno-zachodnia Polska) [Bat censuses 19931999 in Strzaliny (North-Western Poland)]. Nietoperze 3: 17-25.
Bernard, R. \& Samoląg, J. (2002b) Przyczynek do znajomości długości życia nietoperzy w Polsce [Contribution to the knowledge of lifespan of bats in Poland]. Nietoperze 3: 290-293.

Dietz, Ch., von Helversen, O. \& Nill, D. (2007) Handbuch der Fledermäuse Europas und Nordwestafrikas. Biologie, Kennzeichnung, Gefährdung. Stuttgart: Franckh-Kosmos.

Fuszara, E. \& Fuszara, M. (2002) Zimowy monitoring liczebności nietoperzy zasiedlających forty modlińskie na Mazowszu w latach 1989-1999 [Winter monitoring of bats in the forts surrounding the Modlin fortress (central Poland) in the period 1989 to 1999]. Nietoperze 3: 89-99.

Fuszara, E., Fuszara, M., Kowalski, M., Lesiński, G., Cygan, J.P., Nitkiewicz, T., Szarlik, A. \& Wojtowicz, B. (2010) Population changes in Natterer's bat Myotis nattereri and Daubenton's bat M. daubentonii in winter roosts of central Poland. Polish Journal of Ecology 58: 769-781.

Haysom, K., Dekker, J., Russ, J., Van der Meij, T. \& Van Strien, A. (2013) European bat population trends. A prototype biodiversity indi- 
cator. European Environment Agency Technical Report 19/2013. Luxembourg: Publications Office of the European Union.

Horáček, I. (2010) Monitoring bats in underground hibernacula. In: I. Horáček \& M. Uhrin (eds), A Tribute to Bats (pp. 93-108). Kostelec nad Černými lesy: Lesnická práce s.r.o.

Jurczyszyn, M., Gawlak, A., Dzięciołowski, R. \& Kepel, A. (2002) Zimowe spisy nietoperzy w Poznaniu w latach 1979-1999 [Results of winter bat censuses in Poznań in the years 1979-1999]. Nietoperze 3: 77-87.

Lesiński, G., Ignaczak, M. \& Kowalski, M. (2011) Increasing bat abundance in a major winter roost in central Poland over 30 years. Mammalia 75: 163-167.

Stebbings, R.E. (1988) The conservation of European bats. London: Christopher Helm.
Steffens, R., Zöphel, U. \& Brockmann, D. (2007) 40th anniversary Bat Marking Centre Dresden - evaluation of methods and overview of results. Dresden: Sächsisches Landesamt für Umwelt und Geologie.

Van der Meij, T., Van Strien, A.J., Haysom, K.A., Dekker, J., Russ, J., Biala, K., Bihari, Z., Jansen, E., Langton, S., Kurali, A., Limpens, H., Meschede, A., Petersons, G., Presetnik, P., Prüger, J., Reiter, G., Rodrigues, L., Schorcht, W., Uhrin, M., Vintulis, V. (2015) Return of the bats? A prototype indicator of trends in European bat populations in underground hibernacula. Mammalian Biology 80: 170-177.

Wojtaszyn, G., Bernard, R., Jaros, R. \& Samoląg, J. (2008) Zimowe stanowiska nocka Bechsteina Myotis bechsteinii (Kuhl, 1817) na północnej granicy zasięgu [Winter localities of Bechstein's bat Myotis bechsteinii (Kuhl, 1817) at the northern limit of its distribution]. Chrońmy Przyrodę Ojczystą 64(3): 87-91. 